\title{
EL POBLADO FRONTERIZO DE TIJUANA. EMILIANO ZAPATA Y LA RIVOLUZIONE DA TAVOLINO
}

\author{
Marco Antonio Samaniego López \\ Universidad Autónoma de Baja California
}

$\mathrm{F}^{\mathrm{l}}$ presente escrito tiene como principal objetivo demosEtrar cómo los anarquistas del Partido Liberal Mexicano (PLM) y los de Barre, Vermont y Paterson, Nueva Jersey, tuvieron discusiones sobre el movimiento armado que se realizaba en el Distrito Norte de la Baja California y en México. Ello derivó en severas críticas al PLM por parte de anarquistas que en meses anteriores habían realizado esfuerzos para trasladarse desde distintos puntos de Estados Unidos a Tijuana. Por ello, concluyeron que no era necesario que otros realizaran el viaje a México; lo sucedido en la frontera dejó claro que no se trataba de la revolución anarquista que ellos buscaban y que los miembros de la junta del PLM indicaban en los escritos. El calificativo que le dieron los italianos que llegaron a Tijuana desde diferentes partes de Estados Unidos fue que se trataba de una rivoluzione da tavolino, es decir, de mesita, para referirse a la interpretación

Fecha de recepción: 12 de junio de 2015

Fecha de aceptación: 20 de noviembre de 2015 
de que no era la gran revolución social y económica que se relataba en las páginas de Regeneración. Era una revolución inventada, creada en los escritos de sus impulsores, que no cumplía con las expectativas de una de las comunidades anarquistas que hasta ese momento se había destacado en Estados Unidos. Luego de su estancia en el poblado los anarquistas de origen italiano concluyeron que se trataba de un grupo de aventureros americanos, entre los cuales había filibusteros. La paradoja de ello fue que entre los argumentos de los anarquistas italianos del PLM, como Ludovico Caminita, fue que la acusación era cierta, pero no debía quedar la idea de que lo sucedido en Tijuana era la revolución en su totalidad, sino que eran las acciones generadas por bandoleros, unos cowboys americanos. El adjetivo de que se trataba de bandidos apareció en las páginas de Regeneración, versión en italiano. Para Caminita lo sucedido en Tijuana no era relevante, la verdadera revolución anarquista la estaban realizando en todo México personajes como Emiliano Zapata o Juan Banderas. La ayuda de los conscientes, es decir, de los anarquistas, debía llegar de todo el mundo. ${ }^{1}$

De Paterson, Nueva Jersey, había surgido Gaetano Bresci, quien se preparó en dicho lugar para asesinar al rey de Italia, Humberto I. De igual forma, se habían generado huelgas en la industria de la seda. Tenían publicaciones reconocidas como La Questione Sociale y posteriormente L'Era Nuova. Luigi Galleani era uno de los más destacados oradores anarquistas. Desde los primeros años del siglo xx, este personaje fue uno de los más perseguidos por el gobierno

${ }^{1}$ Firmado por Regeneración, "Miserere", Regeneración, sezione italiana (23 sep. 1911). 
estadounidense, entre otras cosas debido a que durante los años de la primera guerra mundial sus seguidores colocaron bombas en varias ciudades. La publicación de mayor relevancia era Cronaca Sovversiva. Entre los galeanistas más conocidos estuvieron Bartolomeo Sacco y Nicolai Vanzetti, mismos que se convirtieron, para unos, en símbolo del movimiento obrero, para otros, en la imagen de los anarquistas asesinos que intentaban llevar a Estados Unidos al comunismo. ${ }^{2}$ Galleani, al escapar de Paterson, permaneció un tiempo en Canadá y en 1907 se trasladó a Barre, en el estado de Vermont. Consideramos importante mencionar que entre las organizaciones que se involucraron con los anarquistas de Paterson estuvo la naciente Industrial Workers of the World (Iww), que también tuvo relación con lo sucedido en el Distrito Norte de la Baja California. ${ }^{3}$

La pugna entre los anarquistas de Barre y su publicación Cronaca Sovversiva y los de Los Ángeles fue de trascendencia en 1911, puesto que los miembros del PLM esperaban el apoyo de italianos y españoles. La esperanza de lograr la revolución mundial tenía como uno de sus objetivos tomar la Baja California, donde se recibiera a anarquistas de Europa y se avanzara sobre todo México para luego trasladar la revolución al mundo. Ricardo Flores Magón, el más conocido de los anarquistas del PLM, a pesar de los mensajes a los socialistas, liberales, miembros de la Iww y otros, tenía como meta provocar la rebelión armada para luego reencauzarla

${ }^{2}$ El surgimiento del Federal Bureau of Investigation (FBI) está ligado directamente a la persecución de Luigi Galleani y sus seguidores. Galleani fue expulsado de Estados Unidos como parte de la campaña del gobierno de Estados Unidos ante el "temor rojo".

${ }^{3}$ Zimmer, Immigrants, pp. 78-79. 
hacia el anarquismo. El término de reencauzar lo tomamos de las páginas de Regeneración.

Dada la estadía permanente en la ciudad de Los Ángeles, California, la relación con las publicaciones de corte anarquista de Europa, Sudamérica y Estados Unidos fue constante. Desde enero de 1911, cuando menos, en Regeneración se hicieron alusiones de que la verdadera lucha era en contra del capitalismo y la burguesía y no sólo contra Díaz. ${ }^{4}$ Si bien varias de sus afirmaciones eran claramente anarquistas, aún se mantenía como bandera el programa del Partido Liberal Mexicano de 1906. En los meses de mayo, junio, julio y agosto se dieron a conocer las pretensiones anarquistas, pero sobre todo el documento del 23 de septiembre de 1911, en el cual se declaró abiertamente la lucha en contra del capital, el clero y toda forma de autoridad. Es decir, en mayo de 1911, momento en que se desarrollaron parte de los acontecimientos que aquí trataremos, ya habían efectuado públicamente las afirmaciones de la revolución mundial, pero no al detalle como en agosto y septiembre de ese año. ${ }^{5}$

La referencia del conflicto entre anarquistas es importante por varias razones. Una, es la idea nunca demostrada del internacionalismo del grupo armado que ocupó de manera temporal los poblados del Distrito Norte de la Baja California. Bajo el nombre equívoco de "magonistas" se ha supuesto que el movimiento era de seguidores de los hermanos

\footnotetext{
${ }^{4}$ Afirmaciones en este sentido existen desde 1904, sobre todo en correspondencia firmada por Ricardo Flores Magón. Sin embargo, en Regeneración corresponde al momento indicado de manera más frecuente.

${ }^{5}$ Respecto de las diferencias internas del PLM, preparamos cuando menos dos textos en los que se demuestran las distintas banderas políticas que procuraban los integrantes del partido.
} 
Flores Magón, cuando muchos de los hombres que tomaron las armas no conocían sus propósitos, no los obedecían, y quienes ejercieron posiciones de liderazgo, no se identificaban con éstos. ${ }^{6}$ Buena parte de los hombres en armas se consideraron maderistas, otros socialistas, y sin duda hubo quienes tuvieron como intención la anexión de la Baja California o una parte de ella a Estados Unidos. Una de las apreciaciones de los italianos es precisamente que el movimiento no tenía liderazgo. Pero sobre todo, quienes se desligaron de los acontecimientos de Tijuana fueron los editores de Regeneración, quienes desconocieron lo sucedido como parte de su movimiento. Los anarquistas de origen italiano que llegaron al poblado fronterizo de Tijuana no pudieron explicar lo que sucedía, desde el punto de vista de los editores de Regeneración, ante los anarquistas de Europa. Otro motivo es profundizar en las contradicciones que se generaron para los anarquistas del PLM al mantener de manera abierta la bandera del programa del PLM, al mismo tiempo que buscaban luchar por el anarquismo. Lo anterior generó críticas de Cronaca Sovversiva, donde se acusó reiteradamente a los integrantes de la junta de Los Ángeles de sostener una revolución política y no dar paso a la verdadera, de carácter económico y social, es decir, anarquista. Consideramos que tanto la discusión con los anarquistas de Barre como la presencia de italianos: Ludovico Caminita y Victorio $L a$ roca Cravello, propició que terminara el doble discurso del PLM y se presentaran definitivamente como anarquistas y

\footnotetext{
${ }^{6}$ De igual forma, los anarquistas del PLM se negaban a ser nombrados "magonistas", puesto que era contrario a su ideología. Para detalles, SAMANiEgo, "'El magonismo no existe”".
} 
por tanto publicaran el documento del 23 de septiembre de 1911, en sustitución del programa de 1906. ${ }^{7}$ Una razón más es analizar los diversos conflictos que enfrentaron de manera simultánea los anarquistas del PLM, quienes debieron luchar en varios frentes. ${ }^{8}$ Los alrededor de cincuenta italianos que llegaron en mayo de 1911, al parecer desde distintos lugares como San Francisco o Palm Springs en California; Seattle, Washington; o la ciudad de Kansas, en el medio oeste, estuvieron unos cuantos días en el poblado fronterizo y se fueron. Se convirtieron en un factor negativo ante la prensa anarquista: no había tal revolución social y económica. Era un movimiento burgués que seguía un plan político como el programa de 1906, y la junta del PLm buscaba ejercer un control sobre el movimiento armado que no era propio de los verdaderos anarquistas. Con ello, la imagen de Emiliano Zapata que se creaba desde entonces en Regeneración no correspondió a lo observado por los italianos. Por tanto, para los editores de la mencionada publicación la mala publicidad realizada por los hombres de Barre abonaba poco a la llegada de anarquistas del mundo. Como veremos, a Galleani lo buscaron los anarquistas del PLM por su

\footnotetext{
7 Para entonces, los miembros no anarquistas del PLm ya se habían sumado al maderismo o mantenían sus luchas socialistas o sindicalistas, sin ser "magonistas".

${ }^{8}$ Debemos tomar en consideración que durante 1911 los anarquistas del PLM enfrentaron a miembros de la misma organización, como Juan Sarabia y Antonio I. Villareal, a Francisco I. Madero, a socialistas de Estados Unidos y a miembros de la International Workers of the World (IWw), a autoridades judiciales y consulares de México y Estados Unidos, así como el desprestigio que conllevó la derrota de un movimiento que no estuvo bajo su control, como lo fue lo sucedido en el Distrito Norte de la Baja California.
} 
prestigio entre quienes seguían dicha ideología, pero al cambiar de opinión sobre lo sucedido, la descalificación de su persona fue constante.

El triunfo de Madero en Chihuahua generó una intensa disputa que provocó la salida de numerosos hombres armados hacia aquel lugar en su apoyo. De igual forma, hubo enfrentamientos entre los diversos grupos de anexionistas que existían en torno de la península de la Baja California. Y sobre todo, la paz en Mexicali se firmó en concordancia con los Tratados de Ciudad Juárez, es decir, como una revolución triunfadora bajo la idea de que el Plan de San Luis era el proyecto que perseguían. ${ }^{9}$ Los indígenas y rancheros locales, dirigidos por Rodolfo L. Gallego y Emilio Guerrero, se tornaron maderistas "tardíos”, como Alan Knigth denomina a aquellos que ante el triunfo de Madero lo apoyaron a pesar de sus filiaciones originales. Uno de los más conocidos fue John Kenneth Turner, autor de México bárbaro, quien en febrero de 1911 apoyaba el movimiento en Baja California, compraba armas y daba instrucciones militares. En mayo solicitó a los anarquistas del PLM, a los dirigentes temporales de quienes ocupaban Tijuana y a sus lectores que otorgaran su apoyo a Francisco I. Madero. ${ }^{10}$

\footnotetext{
9 Samaniego, "El impacto del maderismo", pp. 89-120. Cabe señalar que desde la publicación de este artículo no se ha generado ninguna respuesta de ningún autor que busque negar la demostración de que la paz en Mexicali se realizó de acuerdo con el Plan de San Luis y con la idea del triunfo revolucionario maderista.

10 Samaniego, Nacionalismo y revolución.
} 
REGENERACIÓN, L'ERA NUOVA Y CRONACA SOVVERSIVA: PUBLICACIONES ANARQUISTAS PERSEGUIDAS POR LA LEY

La presencia de anarquistas en Estados Unidos a finales del siglo xIx y principios del xx fue común en varias entidades. Paterson, Nueva Jersey, se destacó por ser una de las comunidades de mayor importancia. Otras ciudades como Tampa, Chicago, Nueva York, San Francisco y Palm Springs, tuvieron actividades de grupos anarquistas que sostuvieron relación tanto con integrantes del Partido Liberal Mexicano como con publicaciones de todo el mundo.

Uno de los temas polémicos fue la denominada propaganda por el hecho, táctica que surgió en Italia desde la década de 1870. Ésta consistió en realizar actos de violencia que llamaran la atención. De ello se derivó el asesinato de príncipes, reyes, primeros ministros y presidentes, sobre todo en Europa. ${ }^{11}$

El suceso de mayor relevancia en relación con los anarquistas en Estados Unidos fue el asesinato del presidente en funciones. El 6 de septiembre de 1901, en la ciudad de Búfalo, Nueva York, William McKinley, recibió dos disparos por parte de León Czolgosz, un joven de 23 años que dijo ser anarquista y haberse preparado para tal acto desde meses atrás. McKinley murió días después, el 14 de septiembre. En los meses siguientes, las declaraciones en contra del anarquismo

11 Novak, "Anarchism and Individual Terrorism”, pp. 176-184. En el contexto europeo la década de 1890 fue intensa en lo referente a la explosión de bombas en varias ciudades. Los nombres François Koeningstein, mejor conocido como Ravachol, Auguste Vaillant y Émily Henry, se volvieron símbolos, para unos, de asesinos anarquistas, para otros, de acciones que se debían imitar para acabar con la opresión capitalista. 
en Estados Unidos fueron intensas. El Congreso aprobó una ley de exclusión de anarquistas Anarchist Exclusión Act, emitida en 1903, en la que estableció la deportación para aquellos inmigrantes que tuvieran opiniones anarquistas.

En el marco de los efectos de la crisis económica de 19071908, que generó desempleo, reducción de salarios y huelgas de mineros, entre otras, se efectuaron actos violentos realizados por anarquistas. Hubo asesinatos de sacerdotes así como atentados en contra de policías en Chicago. A Emma Goldman, anarquista de renombre en esos años, no se le permitió efectuar reuniones ni pronunciar discursos. Para entonces ya era muy conocida por su defensa de León Czolgosz. Como efecto de ello, en meses posteriores el presidente Roosevelt trató el tema como the anarchist problem y se reforzaron las medidas legislativas contra los anarquistas. La prensa comercial generó artículos, comentarios y editoriales en los que se mencionaba a los anarquistas, entre otras cosas, como asesinos por naturaleza. ${ }^{12}$ En ese contexto, se mantuvieron las publicaciones de los anarquistas que aquí destacamos.

Luigi Galleani, editor de Cronaca Sovversiva, apoyó el inicio de la revolución mexicana, pero en especial la que se describía en las páginas de Regeneración. La idea que se empezó a formar este reconocido anarquista - para algunos el más importante de esos años en Estados Unidos - era que en Baja California se desarrollaba la revolución económica y social que culminaría con el comunismo anárquico. Debemos señalar que la referencia a la revolución económica y social es la manera en que los anarquistas se referían a cómo debería ser la revolución, para diferenciarse de los

12 San Francisco Call (30 mayo 1908). 
movimientos políticos y personalistas que encabezaban otros, como el caso de Madero, a quien se referían de esa manera para desacreditar el movimiento.

De acuerdo con Ludovico Caminita, en Paterson, Galleani promovió que miembros de la comunidad hicieran el viaje a Baja California para sumarse al movimiento armado. ${ }^{13}$ Lo mismo hizo Francis Widmar, editor de L'Era Nuova, miembro reconocido en la comunidad anarquista del este de Estados Unidos. Galleani afirmó que ésta no era una revolución política como la encabezada por Francisco I. Madero. Si bien en Regeneración durante los meses de la contienda - enero a junio de 1911 - se mantuvo el discurso de no abrirse totalmente al anarquismo y tratar de mantener la idea de que se luchaba por el programa del PLM de 1906, Ludovico Caminita sostuvo contacto desde California con los anarquistas de Barre y Paterson. Es muy probable que Caminita estuviera en Los Ángeles desde finales de 1910 junto con Victorio Cravello. Al parecer estuvieron entre las filas armadas e hicieron propaganda para buscar que más italianos llegaran a Baja California.

El verdadero nombre de Ludovico Caminita era Michael, sin embargo, debido a la muerte de su hermano Ludovico, adoptó el nombre como suyo. Al igual que Galleani, en Paterson fue editor de La Questione Sociale. Sin embargo, Galleani fue más reconocido por su capacidad oratoria. En la huelga de trabajadores de la industria de la seda en Paterson en 1903, Galleani fue quien encabezó varias

${ }^{13}$ Ludovico Caminita, "Punto e ...daccapo, se sara' necesario", Regeneración, sezione italiana (15 oct. 1911). Cabe señalar que el comentario de Caminita es un reclamo en el que pregunta a Galleani por qué alentó que anarquistas de distintos lugares de Estados Unidos realizaran el viaje. 
de las marchas que se realizaron y fue identificado por las autoridades estadounidenses como peligroso. En numerosas ocasiones dio conferencias en diferentes lugares de Estados Unidos, como Nueva York, Chicago, Búfalo, Pittsburg, Kensington y Spring Valley, por mencionar algunos. ${ }^{14} \mathrm{La}$ Questione Sociale, una de las publicaciones más conocidas entre los anarquistas, fue cerrada por el gobierno de Theodore Roosevelt, luego de que se difundiera un texto en el que se señaló que León Czgolgosz era un héroe. ${ }^{15}$ Por ello, en Paterson apareció L'Era Nuova, misma que formó parte de las discusiones que aquí tratamos.

Es posible que desde 1906 Ludovico Caminita estuviera en contacto con los anarquistas del PLM. En una de las publicaciones realizadas en la comunidad de Home, Washington, aparecieron algunos de sus textos contra la dictadura de Porfirio Díaz. ${ }^{16}$ Tanto Caminita como Cravello tenían ya enfrentamientos con Galleani desde la presencia de éste en Paterson, cuando se convirtió en una figura central. Cravello, quien permaneció varios años como parte de los anarquistas del PLM, se enfrentó en 1908 con Galleani por disposición de recursos que consideraba aplicados en

${ }^{14}$ A. S., "Mentre la mutta fabelica abbaia", Cronaca Sovversiva (4 dic. 1909). En diversas notas de esta publicación sólo aparecen las iniciales.

${ }^{15}$ Ludovico Caminita, "6 Di Settembre", Regeneración, sezione italiana (9 sep. 1911). Cabe señalar que Johann Most también fue encarcelado por justificar el asesinato de McKinley.

${ }^{16}$ Ludovico Caminita, "The Revolutionist", en The Emancipator (nov. 1906); Ludovico Caminita, "The Political and Economical Situation of Mexico", The Emancipator (mayo 1907). Cabe señalar que en dicho lugar se formó una comunidad anarquista que fue sujeto de a diversos ataques por parte de las autoridades locales. 
favor de este último, sin que tuviera atribuciones para ello. ${ }^{17}$ Esto permite ubicar que en cierta medida los conflictos de Galleani con Caminita, Widmar y Cravello, si bien no son la razón principal de las pugnas en 1911, sí influyeron en la manera en que se resignificaron los enfrentamientos que aquí se abordan. Estos mismos actores, cuando menos a finales de 1910 y parte de 1911, trabajaron en función de apoyar la revolución que consideraban podía llevar a una nueva condición a los trabajadores del mundo.

El 20 de mayo de 1911 Cronaca Sovversiva publicó un texto firmado por Ricardo y Enrique Flores Magón, Librado Rivera, Anselmo Figueroa y Antonio de Pío Araujo con el título "Ai lavoratori di tutto il mondo". ${ }^{18}$ Era una traducción de un artículo que apareció en Regeneración el 8 de abril de 1911, "A los trabajadores de todo el mundo", en el cual se indicó que los enemigos eran el capital, la autoridad y la religión. La verdadera revolución era la que terminara con la propiedad privada. El pueblo mexicano ya estaba en la lucha desde hacía cuatro meses. No se trataba de derribar a Porfirio Díaz para llevar a otra persona a la presidencia, sino de una revolución económica y social. No era la revolución política que encabezaba el hacendado, millonario y explotador Francisco I. Madero. El pueblo mexicano

\footnotetext{
17 Ricardo y Enrique Flores Magón, Librado Rivera, Anselmo Figueroa y Antonio de Pío Araujo, Regeneración, sezione italiana, "Punto e...daccapo, se sara' necesario” (21 oct. 1911). Las acusaciones se realizan en los momentos más álgidos de los enfrentamientos entre los anarquistas de Barre y Los Ángeles.

${ }_{18}$ Ricardo y Enrique Flores Magón, Librado Rivera, Antonio de Pío Araujo y Anselmo Figueroa, "Ai lavoratori di tutto il mondo", en Cronaca Sovversiva (20 mayo 1911).
} 
luchaba por tierra y libertad, una de las frases utilizadas por varias agrupaciones anarquistas de diversas partes del mundo. ${ }^{19}$ El llamado, desde las páginas de Cronaca y Regeneración, era a los trabajadores del mundo para sumarse a la causa que había iniciado el pueblo mexicano. Se necesitaba agitar en todas partes ante los hermanos anarquistas, a todos los conscientes, con el fin de sumar revolucionarios a la causa de la lucha contra la burguesía. Se pedía una protesta mundial en el caso de que Estados Unidos interviniera en suelo mexicano. Se solicitó buscar la forma de convencer a los inconscientes y sobre todo recursos económicos para fomentar y mantener la revolución.

Una semana después, el 27 de mayo, en Cronaca Sovversiva se publicó una comparación entre la comuna de París y la revolución mexicana. Desde cualquier ángulo, el comentario era lo esperado por los anarquistas del PLM. Se afirmó que en todo México se impondría el comunismo anárquico. La revolución mexicana era la que llevaría al cumplimiento del ideal propuesto desde Rusia: tierra y libertad. ${ }^{20}$

Sin precisar las fechas podemos afirmar que varios anarquistas italianos estuvieron en Tijuana en los días en que se realizaron las publicaciones mencionadas. Filippo Perrone, Ernesto Teodori, John Luongo, V. Cipolla, Galleotti Guglielmo, Sam Rizzo, Pasquini Guglielmo, A. Paladino,

19 En Barcelona, España, se publicaba el semanario anarquista Tierra y Libertad desde 1903. La relación entre esta publicación y los editores de Regeneración fue de colaboración en 1911. Si bien no podemos establecer el monto de los recursos, por varios comentarios sí podemos afirmar que llegó apoyo económico de dicha publicación española.

20 Liane, "Le due insurrezioni: Parigi, Messico", Cronaca Sovversiva (27 mayo 1911). El comentario sobre el ideal ruso en la página 2. 
Sebastiano Messaglia y otros como Henry Martin, estuvieron en el poblado fronterizo. Es muy posible que cuando menos uno de ellos, Filippo Perrone, estuviera en Mexicali desde antes. En marzo de 1911, Perrone envió un mensaje a Paterson en el que mencionó los problemas para el abasto de armas por la llegada de tropas estadounidenses a la frontera.

El 24 de mayo, en un escrito que no tiene firma, desde Los Ángeles, California, se indicó que el entusiasmo levantado por la revolución en México era muy importante. La nota, titulada "Per i Rivoluzionari del Messico", alentó la participación de los proletarios de todo el mundo para conseguir el comunismo anárquico. En un comentario posterior, se asentó que era con la participación de los anarquistas como se podía lograr que el movimiento revolucionario no se distorsionara y se convirtiera en una lucha por el poder. La revolución debía terminar con todos los privilegios, con la propiedad privada y con la opresión de la ley. Se mencionó que ser llamado bandido era un honor, porque los bandidos luchaban por la libertad. ${ }^{21}$

El 30 de mayo Ernesto Teodori envió un mensaje a Paterson en el que indicaba que no estaban convencidos de que la lucha fuera lo que se esperaba y pedían que al menos por el momento no se pensara en trasladarse para apoyar al movimiento. ${ }^{22}$ De igual forma, se señaló que no debían desanimarse y solicitaba mantener el apoyo económico al comité

${ }^{21}$ Liane, "Per i Rivoluzionari del Messico", Cronaca Sovversiva (3 jun. 1911). Como apuntamos, el escrito está firmado el 24 de mayo.

22 "Inqualificable", Regeneración, sezione italiana (7 oct. 1911). Menciona el texto: "Recatici sul longo, siamo costretti a sconsigliare i compagni di ricarsi nel Messico, almeno por il momento, giache la lotta che ivi si combatte non é quella che noi ci aspettavamo. Non ocorre che disanimate 
revolucionario. El 3 de junio, en Cronaca Sovversiva, apareció una nota que relata la conferencia de Libero Tancredi en Cleveland, Ohio, en la que se alentó a la revolución mexicana tomando como referencia la comuna de París y se mencionó que la revolución de Madero era burguesa, pero se daría paso a la verdadera revolución. ${ }^{23}$ En ese mismo número apareció la nota ya mencionada enviada desde Los Ángeles el 24 de mayo y el comentario adicional señalado en el párrafo anterior. Ese fue el último escrito en favor de la revolución mexicana en Cronaca Sovversiva.

El 17 de junio, Cronaca Sovversiva publicó un breve escrito signado por Filipo Perrone, Ernesto Teodori, John Luongo, V. Cipolla, Galleotti Guglielmo, Sam Rizzo, Pasquini Guglielmo y A. Paladino, en el cual indicaron que la revolución mexicana no era una revolución económico social; en realidad el Partido Liberal tenía objetivos financieros. Era una revolución da tavolino, es decir, de mesita, inventada por los miembros de la junta de Los Ángeles, California. ${ }^{24}$ Para los miembros de la junta y en especial para Ricardo Flores Magón la publicación fue considerada una traición. La relación con los anarquistas italianos se debía a la idea - manifestada en varias ocasiones - de recibir apoyo

i compagni del mandare le loro contribuzioni finanzierie al Comitato revolucionario".

${ }^{23}$ Ugo Balzano, Cronaca Sovversiva (3 jun. 1911). La nota no tiene título. Es una relatoría de la conferencia de Libero Tancredi en favor de la revolución en México. La aseveración es que esta era una revolución anarquista.

${ }^{24}$ Filippo Perrone, Ernesto Teodori, John Luongo, V. Cipolla, Galleotti Guglielmo, Sam Rizzo, Pasquini Guglielmo, A. Paladino, "Gli anarchici e la Rivoluzione messicana. Da quelli che ci sono stati”, Cronaca Sovversiva (17 jun. 1911). 
de europeos anarquistas para el logro del objetivo. El 3 de mayo de 1911, Ricardo escribió a Pedro Esteve, anarquista español radicado en Cuba, que ya se tenía tomado el poblado de Tijuana, lo que para ese momento no era cierto. Mencionó que en la península se podía realizar la expropiación de la tierra para ser el ejemplo a seguir. Posteriormente indicó:

Así, pues, urge que vengan a la Baja California muchos anarquistas de todas partes del mundo para que apoyen la expropiación de la tierra y de la maquinaria. Hay en la Baja California tierras preciosas, minas muy ricas y puertos magníficos. En manos de los libertarios la Baja California se sacarán de ella elementos bastantes para llevar la revolución a todo México y aún al mundo entero, porque es muy grande la península y muy rica; pero está muy poco poblada. ${ }^{25}$

Por ello, si en semanas anteriores desde Paterson y Barre, Luigi Galleani y Francis Widmar animaban a italianos anarquistas a sumarse al movimiento armado que se realizaba en México, en los siguientes meses se realizó una agria disputa entre los anarquistas del PLM de Los Ángeles contra anarquistas de Barre, con comentarios de miembros de grupos de Paterson, Kansas, Spring Valley, Tampa, San Francisco y otros lugares. Se discutió si la revolución mexicana era económico social, que llevaría al comunismo anárquico, o era da tavolino, inventada en las páginas de Regeneración, en especial por Ricardo Flores Magón, para recolectar fondos y ser, como se llegó a mencionar, un burgués con seguidores que lo adoraban a pesar de ser un egoísta petulante.

${ }^{25}$ Ricardo Flores Magón a Pedro Esteve, 3 de mayo de 1911, en archivo electrónico de Ricardo Flores Magón, Instituto Nacional de Antropología e Historia, 1911-1927. 
Una de las respuestas inmediatas por los anarquistas del PLM fue iniciar la publicación de Regeneración sezione italiana, cuyos ejemplares aparecieron de julio a octubre de 1911, en total 16 números. De igual forma, en varios ejemplares de Regeneración en español, hubo un espacio en italiano. Ludovico Caminita fue el editor y quien confrontó a Filippo Perrone y sobre todo a Luigi Galleani para aclarar ante los anarquistas de todo el mundo la afrenta de señalar que la revolución mexicana, dirigida en el campo de batalla por hombres como Emiliano Zapata, Juan Banderas e Inés Salazar, no era de carácter económico social, sino da tavolino. La paradoja de ello es que en los propios argumentos de Regeneración, se llegó a decir que lo sucedido en Baja California había sido obra de 400 vagabundos americanos y los acontecimientos en Tijuana no representaban lo que sucedía en todo el país: ese no era su movimiento.

\section{POR QUÉ LA RIVOLUZIONE DA TAVOLINO}

¿Qué presenciaron los anarquistas italianos que llegaron de diversos puntos de Estados Unidos para hacer la afirmación de que se trataba de una revolución inventada en las páginas de Regeneración, en particular por la pluma de Ricardo Flores Magón? De antemano, señalamos que la respuesta está ligada a las conclusiones que hemos publicado en otros textos: 1) hubo objetivos distintos entre quienes ocuparon temporalmente las poblaciones de Mexicali, El Álamo y Tijuana; 2) asignarles el término de "magonistas", de "la otra revolución", "la verdadera revolución", "la campaña magonista”, no permite observar que no se trató nunca de un grupo unido, que intentara seguir la ideas no definidas del PLM, 
ya que por un lado se llamó a seguir el Programa de 1906 a socialistas, a miembros de la Iww, y como aquí se demuestra a uno de los sectores de anarquistas más conocidos en esos años en Estados Unidos; 3 ) sin duda en el contingente armado hubo individuos que, sin integrarse como grupo, buscaban la anexión de una parte de la Baja California o de toda la península a Estados Unidos; 4) las presiones por la anexión o no de una parte del valle de Mexicali era el tema más recurrente debido a la inversión de 1000000 de dólares que realizaba en ese momento el gobierno federal de Estados Unidos en territorio de México. Empresarios, publicaciones, agricultores y funcionarios de gobierno manifestaron que la anexión era el resultado lógico y natural de las acciones armadas que se efectuaban en el norte de la península; 5) no existía entre los hombres en armas una diferenciación entre una revolución de Madero y otra de Flores Magón, para los extranjeros que combatieron su lealtad fue mínima o inexistente.

Para ubicar lo que observaron los anarquistas italianos hacemos un brevísimo resumen. De enero a abril, Mexicali fue el centro de las acciones. Numerosos extranjeros desconfiaron del liderazgo de los mexicanos y formaron la legión extranjera. En los combates no lucharon de manera coordinada e incluso, el 8 de abril, Stanley Williams se enfrentó a las tropas federales contra la decisión del supuesto jefe mexicano Francisco Vázquez Salinas. Las pugnas se volvieron comunes y sectores del grupo armado se fueron de Mexicali debido a los constantes enfrentamientos. Un grupo, al mando de Simón Berthold, llegó al poblado minero de El Álamo en la sierra, pero las divisiones impactaron y los indígenas que se sumaron a la Revolución abandonaron al grupo. 
En mayo, Carl Ap Rhys Pryce, contraviniendo las órdenes de la Junta de Los Ángeles, ocupó el poblado de Tijuana. Por su condición inmediata a la línea divisoria se convirtió en un foco de atención de varios cientos de sandieguinos, así como de la prensa estadounidense. En los alrededores, entre rancheros y trabajadores en las vías del ferrocarril, la mayoría extranjeros, vivían cerca de 1000 personas. Debido a que el poblado se tomó el mismo día que Ciudad Juárez, el hecho fue magnificado por la prensa. En Mexicali permanecieron los mexicanos, muchos de los cuales se tornaron maderistas a finales de mayo y principios de junio.

El tópico de mayores especulaciones fue la anexión. Si dicho asunto era una constante casi cotidiana desde finales del siglo XIx, en esos meses fue el gran tema de numerosas publicaciones, tanto de los centros financieros como de representantes políticos, empresarios y agricultores de Arizona y California. En Tijuana se izó la bandera roja que simbolizaba el anarquismo, pero también varias de Estados Unidos.

No tenemos conocimiento preciso del día en que llegaron los anarquistas italianos. Sin embargo, por lo asentado por quienes dejaron testimonio, fue en los últimos días de mayo. Es decir, conocieron las especulaciones que hemos mencionado. El 21 de mayo se firmaron los llamados Tratados de Ciudad Juárez. Con ello se reconoció el triunfo de Madero y, por tanto, la ola del maderismo tardío generó mayores tensiones al contingente que con diferentes intereses ocupaba Tijuana y Mexicali. El ánimo de haber triunfado se contrapuso con la idea de que la revolución apenas empezaba, es decir, la verdadera, la anarquista, la que se pronosticaba en Regeneración. A pesar de las aclaraciones realizadas desde febrero de que 
no se luchaba por lo mismo, las acciones de los ocupantes del poblado reflejan no haberlas conocido o no entenderlas.

El 28 de mayo, los indígenas kiliwa y paipai, al mando de Emilio Guerrero, llegaron a Tijuana. De inmediato se convirtieron en el centro de atracción de los turistas y de la turbulencia de los siguientes días. Francisco Pacheco, un integrante del grupo de Guerrero que no era indígena, fue asesinado por Eulalio Baeza, un estadounidense conocido en la zona fronteriza. Este hecho generó una intensa disputa entre mexicanos y estadounidenses. Pryce organizó un juicio en el que salió libre Baeza, pero los indígenas de Baja California se negaron a aceptar el veredicto y obligaron a su ejecución. Pryce no logró imponer su autoridad y la noche del 30 de mayo se fue para no volver. Días después afirmó que nadie le hacía caso, lo que era cierto. Como ya apuntamos, ese mismo día Ernesto Teodori, desde Tijuana, indicó que cuando menos por el momento no viajaran más anarquistas, pero sí debía mantenerse el apoyo económico.

El contingente armado se dividió en tres facciones, mexicanos e indios por un lado, estadounidenses por otro y extranjeros en general. La discusión acerca del liderazgo se tornó violenta. Louis James, uno de los más cercanos a Pryce aprovechó el momento para mostrar su interés de anexar. James se puso en contacto con Ferris, quien llegó a Tijuana la mañana del viernes 2 de junio. Ferris declaró ante un grupo de insurgentes que debían arriar la bandera roja ya que para Estados Unidos eso significaba anarquía. Afirmó que debían terminar con su anarquismo y socialismo para formar un nuevo gobierno. Para ello, apelarían a sangre joven de Estados Unidos y a la prensa de dicho país, sólo así podrían conseguir apoyo económico de algunos capitalistas. Indicó que algunos 
mexicanos de la mejor clase podrían llegar a unírseles. Aseguró que el nuevo Estado se llamaría República de Madero y que de ser posible se le daría una compensación económica al gobierno mexicano. Momentos después, Ferris fue proclamado presidente de la nueva república, pero no aceptó.

No entraremos en detalles de los días siguientes, sólo mencionaremos que el 5 de junio Louis James intentó colocar la bandera de la nueva república en Tijuana. Los mexicanos, y sobre todo los indígenas dirigidos por Emilio Guerrero, quemaron la bandera y estuvieron a punto de darle muerte a James. La intervención de varios estadounidenses, alrededor de 50, evitó que fuera asesinado.

\section{LA REVOLUCIÓN MEXICANA ¿DA TAVOLINO?, ¿SOCIAL Y ECONÓMICA?}

Como apuntamos, este escenario es el que generó que los anarquistas italianos, desde el 30 de mayo, afirmaran que lo sucedido en Tijuana no era la revolución económica y social a la que se aludía en Regeneración. Con la publicación del 17 de junio la polémica fue clara: era una rivoluzione da tavolino, inventada, exagerada por la pluma de los anarquistas de la Junta de Los Ángeles, quienes sólo procuraban allegarse recursos para sus fines personalistas. Sobre todo, financiar la publicación de Regeneración, sezione italiana, al frente de la cual estaría Ludovico Caminita.

Con ello, surgió uno de los temas en que en los años siguientes se insistió en las páginas de Regeneración: la falta de solidaridad de los anarquistas. De igual forma, de esta polémica aparecieron las referencias a negar la bandera del Programa del Partido Liberal Mexicano de julio de 1906, así 
como denostarlo y llamarlo rancio. En los meses posteriores un argumento de Galleani fue que los burgueses del PLM tenían un programa capitalista, republicano y demócrata, es decir, eran una revolución política, lo que para los anarquistas del PLM era un insulto.

Por ello la definición de qué revolución era se volvió un asunto fundamental. Para los anarquistas del PLM era importante la llegada de ácratas de Europa, pero con los comentarios de los italianos de Barre y los que llegaron a Tijuana los libertarios dudarían en realizar el viaje. Si bien existen numerosos ejemplos, apuntamos sólo uno de ellos. Luego de la toma de Veracruz por tropas estadounidenses, el 25 de abril de 1914, en la nota "La leva revolucionaria", signada por "Un libertario", se llamó insistentemente a los anarquistas europeos a defender la lucha de los revolucionarios mexicanos contra el capitalismo. Los delegados que fueran a Europa sembrarían la importancia de la lucha social agraria. Llegarían los europeos a invadir - es la palabra que se utiliza - México y apoyarían la liberación del productor esclavizado. Se afirmó que los europeos tendrían los mismos derechos que los mexicanos. Posteriormente se indicó:

Por todos conceptos, pues, el proletariado debiera hacer suya la Revolución mexicana y el esfuerzo del proletariado mundial debe ser unánime y extremo. Los revolucionarios deben organizarse y formar una avalancha de hombres bien pertrechados y hacer irrupción en México, y al lado de aquellos gigantes que luchan por TIERRA Y LIBERTAD aplastar el pulpo del pasado. ${ }^{26}$

${ }^{26}$ Un libertario, "La leva revolucionaria”, en Regeneración (25 abr. 1914). 
Posteriormente se afirmó que el territorio mexicano era suficiente en recursos naturales y en cantidad de tierras para recibirlos sin necesidad de enfrentamientos. En Europa quedaría la burguesía y en México el proletariado. Al respecto de ello no ahondamos en este escrito. Sin embargo, resulta claro que la pretensión era atraer al proletariado europeo. Por lo anterior, en 1911, cuando se consideraba que era necesario reencauzar la revolución burguesa de Madero, ser acusados de que no había tal revolución económico social, es decir, anarquista de acuerdo con sus conceptos, resultaba una afrenta que era necesario aclarar.

Por ello, ante la referencia de que era una revolución de mesita, inventada en las páginas de Regeneración, Ludovico Caminita, Victorio La roca Cravello y Ricardo Flores Magón, atacaron a los firmantes de la nota, en especial a Filippo Perrone. En julio de 1911, tanto en las páginas de Regeneración en español como en italiano - el primer número es del 15 de julio - se menciona que la revolución mexicana, de corte anarquista, marchaba por todo el país. En ejemplares de septiembre y octubre de 1911 se manifestó que Emiliano Zapata con sus 4000 hombres expropiaba la tierra y la entregaba a los campesinos. ${ }^{27}$ Emilio Guerrero, quien lideró a indígenas kiliwa y paipai de la sierra y fue un factor significativo en los acontecimientos de finales de mayo, mencionados páginas atrás, supuestamente, a mediados de septiembre había tomado Baja California. ${ }^{28}$ Cabe

${ }^{27}$ Ludovico Caminita, "Movimento sociale internazionale", Regeneración, sezione italiana (2 sep. 1911).

28 "Ancora una", Regeneracion, sezione italiana (16 sep. 1911). En la nota, sin autor, se afirma lo siguiente: "la banda du Guerrero che opera nella Bassa California se accresciuta di altri cinquanta uomini. Essa a 
señalar que para ese momento Guerrero se había sumado a Rodolfo L. Gallego, ranchero local que tomó la bandera de Francisco I. Madero de junio de 1911. Dicho de otra manera, Guerrero, como muchos otros de los hombres en armas en Baja California, terminó su participación en la revolución triunfante de Madero..$^{29}$ Sin embargo, fueron mencionados como la prueba de que la revolución anarquista estaba en marcha. Un ejemplo es que en el primer número de Regeneración, editado por Caminita, al realizar la narración de los avances de anarquistas según su afirmación, intituló el escrito: "Movimento sociale internazionale". En los primeros párrafos se afirmó que el avance de la revolución era indiscutible y se debía a los seguidores del PLM. El crecimiento de la revolución anarquista era enorme y el proletariado mexicano lograría infundir en el internacional los ánimos para luchar y acabar con toda forma de autoridad. Se efectuaría el gran incendio que culminaría con la formación de una nueva humanidad. La nota fue signada por Lucifero. ${ }^{30}$

Por ello, la intención de los miembros de la junta de Los Ángeles, California, fue que los italianos que estuvieron

assalito le truppe di Madero e le a preso due cannoni. Sono ottanta uomini ora che aventolano la bandierra rossa nella Bassa California, decisi a vincere o morire". Sin embargo, Guerrero se pacificó en Mexicali como maderista. El triunfar o morir fue solo en el papel.

${ }^{29}$ Samaniego, "El impacto del maderismo en Baja California, 1911", pp. 89-120. Sobre Emilio Guerrero, Samaniego, "La rebelión indígena de Emilio Guerrero en Baja California”, pp. 114-131.

${ }^{30}$ Lucifero, "Riassunto", Regeneración, sezione italiana (15 jul. 1911). Entre varios anarquistas, las alusiones al demonio son frecuentes para oponerse a los principios cristiano católicos. Así, por ejemplo, un hijo de Enrique Flores Magón llevó por nombre Demonico. Falleció al poco tiempo de nacido. Sin embargo, también es posible afirmar que las alusiones a Cristo son frecuentes. En Ricardo se vuelven reiterativas. 
en Tijuana cambiaran su afirmación. Promovieron el apoyo de L'Era Nuova de Paterson, Nueva Jersey y su editor, que había financiado el traslado de italianos a Baja California, Francis Widmar. Este apoyo en efecto llegó por parte de la mencionada publicación y en los meses siguientes se enfrentaron a Cronaca Sovversiva. Widmar, con narraciones en las que se apoyó el tema de que en efecto se trataba de una revolución económico social, y Cronaca Sovversiva, que era una revolución política, inventada sobre todo por Ricardo Flores Magón y en ratificación de que era da tavolino. Ludovico Caminita y Victorio La roca Cravello se mantuvieron en apoyo de Regeneración y al frente de la versión en italiano. Participaron con opiniones anarquistas de Kansas, Tampa o Palm Springs. De manera tangencial mencionamos que Appeal to Reason, ${ }^{31}$ de corte socialista, intervino con información de índole personal, dado el apoyo otorgado a Madero. Se acusaba a Ricardo de vivir con una mujer que no era su esposa y se utilizaron adjetivos como ambicioso e impostor. Estos señalamientos fueron utilizados por Galleani para acusar de vividor a Ricardo y reclamarle que se quedara en Los Ángeles sin acudir a la lucha armada. Fue parte de las referencias de que en realidad le interesaban los recursos económicos y que era tratado como un rey con su corte. Por su parte, desde Regeneración se argumentó en el sentido de que los constantes ingresos a la cárcel por parte de los miembros de la junta eran la prueba de la autenticidad de sus propuestas contra toda forma de autoridad.

${ }^{31}$ Es frecuente que se mencione el apoyo de esta publicación a la Junta Liberal de Los Ángeles, pero de manera semejante a otras organizaciones o personajes que se atribuyen como seguidores del PLM o "magonistas", la publicación apoyó a Madero. 
Por su parte, John Luongo, Guglielmo Pasquini, Filippo Perrone y otros de los firmantes del documento que publicaron lo referente a la revolución da tavolino, mantuvieron sus afirmaciones entre sus correligionarios. El 1ํ de julio, en Cronaca Sovversiva, indicaron que simpatizaban y respetaban a la junta de Los Ángeles, pero el movimiento que realizaban era totalmente fallido. Ratificaron su afirmación; era una invención en la mesita de redacción. ${ }^{32}$ John Luongo, firmante del escrito del 17 de junio, de Kansas, indicó que Jack Mosby se fue de Tijuana sin disparar un solo tiro e ironizó que un desertor del ejército de Estados Unidos fue quien instituyó el comunismo. ${ }^{33}$

Consideramos que el texto "Buon Senso, Coraggio e costanza”, firmado por Caminita en la edición del 1ํ de julio de 1911, permite entender distinciones que los anarquistas del PLM querían comunicar a sus correligionarios. Debemos tomar en consideración que desde abril de 1911 el llamado fue constante a los proletarios del mundo, aunque el manifiesto anarquista es de septiembre. Caminita realizó aclaraciones en respuesta a la afirmación de que se trataba de una revolución da tavolino. Por un lado señaló que no debió esperarse que en Tijuana varios miles de hombres estuvieran cantando el himno del anarquismo. Un supuesto ejército conformado por anarquistas de todas las lenguas y dispuestos a morir hasta vencer. Posteriormente, hizo una afirmación de particular importancia. Indicó que Tijuana

\footnotetext{
32 “Messicana”, Cronaca Sovversiva (1º jul. 1911). El texto no tiene firma, pero quien lo redactó asume que tiene la representación de todos los firmantes del documento del 17 de junio.

33 Ludovico Caminita, "John Luongo", Regeneración, sezione italiana (22 jul. 1911).
} 
no era México, por tanto, no se podía juzgar al movimiento por unos 300 vagabundos estadounidenses que sólo perseguían un botín. A ello volveremos más adelante, ya que desde Regeneración, sezione italiana se despreció de manera clara lo realizado por los hombres en armas que ocuparon Tijuana en lo específico y que para algunos autores son los supuestos "magonistas”, los que integran la "campana magonista”, la “otra revolución”. ${ }^{34}$ Caminita señaló que los conscientes no debían negar hombres o dinero para el Partido.

Caminita enumeró cuatro puntos: 1) Los miembros de la junta no sugirieron a nadie ir a México. Ellos no habían pedido la llegada de hombres, sino dinero para la compra de armas. 2) Los que quisieron presentarse lo hicieron de manera espontánea sin conciliarlo con la junta. Los que llegaron a los Ángeles esperaban obtener recursos, como si éstos llegaran del cielo, como si fueran maná. Ahora gritaban contra Magón, Cravello y Caminita, como si los hubieran engañado. 3) Si Tijuana era un lugar con pocas casas y en la guerra cuenta el número de casas, ¿qué da mayor o menor importancia a un lugar? 4) En Tijuana, los que dominaban el movimiento eran aventureros desde el principio, “eso es cierto”. ¿Qué culpa tenían el comité o la junta? Señaló Caminita que no eran un gobierno, no ejercían autoridad sobre los combatientes. Éstos actuaban de manera independiente, sin influencia. No estaba en su poder cambiar o

${ }^{34}$ Martínez, El magonismo; Blaisdell, The Desert Revolution; BlanQUEL, "El anarco-magonismo"; HernÁNdez, El magonismo; Torres, La revolución sin fronteras; TAYLOR, La campaña magonista; TrEJO, Magonismo. Señalo sólo estos aunque existen muchos más autores que admiten que lo sucedido en Baja California es de seguidores de Ricardo Flores Magón. 
destituir a otros, ni disolver o formar otra división. Su tarea era formar el Partido Liberal Radical, que no se componía sólo de anarquistas, socialistas o tolstoianos - en referencia a León Tolstoi-, sino de todos los elementos heterogéneos que estuvieran de acuerdo en un solo programa: la socialización de la tierra y de todas las herramientas de trabajo: la abolición de toda autoridad política. ${ }^{35}$

Así, pues, en Regeneración, en nota en italiano, en julio de 1911, se afirmó que la lucha del Distrito Norte de la Baja California, y en específico de Tijuana, fue sustentada por 300 vagabundos estadounidenses. Por otra parte, no debemos dejar de lado que en ese momento Ricardo y Enrique Flores Magón, Anselmo Figueroa y Librado Rivera enfrentaban cargos por violación de las leyes de neutralidad, por lo que estaban interesados en no reconocer lazos con los hombres que ocuparon Tijuana. Sin embargo, también es claro que su interés era demostrar que el fracaso de Baja California no se debió a ellos, sino a los aventureros estadounidenses que no seguían sus instrucciones. Pero sobre todo, que no se comparara a esos vagabundos - para usar sus términos - con los verdaderos revolucionarios que en otras partes del país efectuaban la anhelada revolución económica y social: Inés Salazar, Juan Banderas, Emiliano Zapata. Era necesario apoyar esa lucha. Y se necesitaba dinero, armas y anarquistas que llegaran con intenciones de realizar la revolución mundial, no de criticar lo sucedido con los vagabundos de Tijuana. Por otra parte, estas afirmaciones corroboran nuestras conclusiones en el sentido de que, en efecto, los hombres en armas

${ }^{35}$ Ludovico Caminita, "Buon Senso, Coraggio e Costanza”, Regeneración (1 ${ }^{\circ}$ jul. 1911). 
no siguieron instrucciones de la junta y no conocían sus pretensiones. También explica por qué en Mexicali se volvieron a favor de Madero y en la misma Tijuana hubo numerosos abandonos para trasladarse a Ciudad Juárez, donde se registró el triunfo buscado tanto por extranjeros como por mexicanos, que no comprendieron las diferencias entre lo planteado por Madero y lo buscado por el PLM, a pesar de las declaraciones de Ricardo en el sentido de que se trataba de dos movimientos diferentes. ${ }^{36}$ En la edición siguiente de Regeneración, el 8 de julio, Caminita publicó el texto firmado por Perrone y los ya mencionados del 17 de junio y mantuvo la postura de que la revolución social y económica en México se mantenía en marcha. Si bien Tijuana era un caserío sin importancia, con apenas 150 personas, la propuesta anarquista era seguida en todo el país. Cabe señalar que en los ejemplares de Regeneración los movimientos armados en diferentes regiones eran publicitados como parte del movimiento del PLM. ${ }^{37}$ Caminita, además, aclaró que Figueroa, Rivera y los hermanos Flores Magón apenas cobraban un dólar diario por todo el trabajo que hacían, por lo que mencionar los intereses financieros de los miembros de la junta era absurdo.

Siguiendo esta línea, durante los siguientes años es frecuente encontrar notas tituladas "para los que dudan”, es decir, para aquellos que no creían en la revolución económico social. De igual manera, en alusiones directas a lo que sucedía en algunas entidades del país, sobre todo en Morelos, la interpretación que se daba era en ese sentido:

36 Samaniego, "El impacto del maderismo".

37 Ludovico Caminita, "Perrone e compagni”, Regeneración (8 jul. 1911). 
se trataba de un movimiento que expropiaba la tierra y los medios de producción en general. Era el comunismo anárquico que los mexicanos ya habían practicado y que regresaba luego de algunos años. Los italianos seguidores del "marrano" Galleani, pocos según su decir, eran envidiosos, malos anarquistas que llenos de teorías inútiles no ayudaban al triunfo del anarquismo. Rafael Romero Palacios, que por un breve tiempo dirigió Regeneración, el 8 de julio mencionó las numerosas publicaciones de corte anarquista que los apoyaban. Proporcionó una larga lista y señaló cómo la labor del PLM era atacada por unos italianos que,

[...] flagelando duramente a los que hasta ahora han traicionado a la causa, especialmente a un grupo de cinco o seis de los que últimamente lo han hecho, y que para justificar su cobardía andan haciendo mala propaganda entre el elemento italiano, sin pensar que ningún libertario de verdad dará oído a sus necias justificaciones y sin medir la responsabilidad que para la causa contraen con su proceder. ${ }^{38}$

En ese mismo número, Ricardo Flores Magón expuso ejemplos de que la prensa burguesa daba información sobre el avance de la revolución económico social, por lo que ningún calumniador podría decir

[...] que la Revolución Social en México existe en nuestra calenturienta imaginación, para que se nos cierren todas las puertas y nadio $[s i c]$ se desprenda de una moneda para ayudar a sus hermanos.

${ }^{38}$ Rafael Romero Palacios, "Movimiento de solidaridad", Regeneración (15 jul. 1911). 
Escupid al rostro a todos aquellos que fingiéndose anarquistas, socialistas o simples amigos de la clase trabajadora niegan que hay Revolución Económica en México y ayudad al Partido Liberal Mexicano que tiene la audacia de enarbolar la Bandera Roja del proletariado en campo virgen. ${ }^{39}$

En esta tónica sintetizamos para los efectos de este escrito una idea que para los anarquistas del PLM era indiscutible: la revolución era anarquista.

Con la aparición de Regeneración, sezione italiana dejaron de publicarse textos en italiano en Regeneración. Durante julio y agosto de 1911, cuando los miembros de la junta entraron y salieron de la cárcel en varias ocasiones, Caminita publicó textos sobre el heroísmo de Kropotkin, Gaetano Bresci, León Czolgosz, Ravachol, Émily Henry y Vaillant, todos ellos vinculados a la propaganda por el hecho mencionado páginas atrás. Así mismo, aparecieron notas sobre movimientos sociales de trabajadores en Inglaterra, Francia, Alemania, Italia. La intención era sugerir que alrededor del mundo se gestaba un movimiento internacional. De igual forma, retó a Galleotti Guglielmo, uno de los firmantes de la aseveración de que se trataba de una revolución da tavolino, a que acudiera a México para que observara cómo en realidad sí era una revolución económico social. Sin embargo, los insultos fuertes se dirigieron a Luigi Galleani. Era, según Caminita, un imbécil, se creía un genio, el gran cardenal del anarquismo ítaloamericano, cuando su única virtud intelectual era haber sido secretario de Élisee Reclus. ${ }^{40}$ No

39 Ricardo Flores Magón, “La burguesía temblando”, Regeneración (15 jul. 1911).

40 "At last", Regeneración, sezione italiana (19 ago. 1911). La nota no 
debía comparar los enormes logros que se daban en México con las constantes expropiaciones de la tierra - que afirmaban sucedían una tras otra - con la triste huelga dirigida por Galleani en 1903 en Paterson, donde apenas se logró un pequeñísimo aumento de salario. Ernesto Teodori polemizó directamente con Caminita, en el sentido de mencionar que los de la junta sólo tenían motivos financieros, por lo que eran unos ladrones.

El 19 de agosto, firmado por la junta del Partido Liberal Mexicano, se inició la distribución de un documento en el que se argumentó contra Galleani en diversos sentidos. Desde explicaciones de que los indígenas en México siempre habían sido comunistas, hasta culpar a Galleani de que el proletariado internacional no llegaba a combatir por sus afirmaciones contra la revolución anarquista que se realizaba en México. Aun así, sus difamaciones no detendrían la inevitable derrota del capitalismo y la toma de la tierra que ya se efectuaba en México. ${ }^{41}$

SEPTIEMBRE DE 1911: ¿DE QUÉ REVOLUCIÓN SE TRATA?

Durante el lapso en que los anarquistas del PLM fueron liberados y enfrentaron el juicio por violación a las leyes de neutralidad, las acusaciones contra los anarquistas de Barre fueron más intensas y en sentido opuesto; la aseveración de que la revolución económico social estaba sólo en la mente

tiene firma, pero por la forma en que se refiere a Galleani y a Francis Widmar, es evidente que conoce las condiciones que se vivieron en Paterson años atrás. Por ello, todo indica que se trata de Ludovico Caminita. ${ }^{41}$ Ricardo Flores Magón, “'Terra e Libertà’, Regeneración, sezione italiana (9 sep. 1911). 
de los redactores de Regeneración se repitió con insistencia. En estos meses se publicaron en torno de esta polémica dos líneas que consideramos de significación para discutir la estrategia del PLM. La primera, el 23 de septiembre de 1911, cuando se publicó el manifiesto en que se declararon abiertamente anarquistas. La segunda, cuando afirmaron que el programa de 1906 no era su bandera, pues era un programa rancio y burgués que no los identificaba con su verdadera lucha. Meses atrás, el 6 de mayo, se había publicado que el autor del programa era Juan Sarabia, charalito, aunque Ricardo indicaba su influencia en el mismo. La discusión era de suma relevancia para los anarquistas del PLM, ya que era responder a las preguntas de posibles adherentes a una lucha armada que ellos estaban seguros se realizaba en México. Como ya apuntamos, los anhelados anarquistas europeos no llegarían si estaban mal informados y no se reconocía que el movimiento era económico social. Galleani y los firmantes del documento insistieron: era una revolución política que no valía la pena. La rectificación solicitada no se realizaría.

Luigi Galleani, el 7 de agosto, en Boston, manifestó que la idea del contagio revolucionario tenía sentido, aunque fue poco optimista respecto al proletariado estadounidense. La única forma posible de realizar el verdadero cambio era con la destrucción del sistema imperante, es decir, la toma de todos los medios de producción. ${ }^{42}$ En septiembre, tanto Galleani como Ernesto Teodori, Filippo Perrone y John

${ }^{42}$ Luigi Galleani, "La tormenta messicana", Cronaca Sovversiva (19 ago. 1911). Se reproduce la plática ofrecida el 7 de agosto en Boston, Massachusetts. 
Luongo ratificaron sus afirmaciones en Cronaca Sovversi$v a$, de las que se desprende que algunos textos fueron dados a conocer en otras publicaciones anarquistas. En resumen, plantearon que sentían pena por la revolución dadas las esperanzas que despertó, pero era inexistente: era una revolución magnificada sólo en papel. La simpatía estaba con la junta de Los Ángeles, pero sus integrantes eran a final de cuentas burgueses, autores del programa del Partido Liberal Mexicano. Una prueba de que no pasaba de ser una revolución burguesa liberal fue la publicación de las instrucciones generales a los revolucionarios, de enero de 1911, en las que sus autores sólo se mostraban, desde su punto de vista, como autoritarios. ${ }^{43}$ Por ello, en Cronaca se publicaron ambos textos como prueba de que ese programa era tristemente reformista, burgués, nacionalista, republicano, es decir, todo aquello contra lo que luchaban los verdaderos anarquistas.

El testimonio de John Luongo en septiembre de 1911 fue que entre las tropas que ocupaban Tijuana reinaba el desánimo, la falta de conocimiento del anarquismo, así como armas y municiones. En cambio sobraban el alcohol y las prostitutas en las calles. Adolfo Antonelli, quien presumiblemente tomaría la dirección del movimiento, conversó con dos de los integrantes y quedó decepcionado. En San Diego, California, indicó a Luongo que esa revolución no era su causa. ${ }^{44}$ La gente luchaba por Bernardo Reyes o por Madero, no por el anarquismo. Por nuestra parte, resaltamos que el

${ }^{43}$ Luigi Galleani, “Lo vogliono proprio?”, Cronaca Sovversiva (2 sep. 1911).

${ }^{44}$ Luigi Galleani, "Poiché Lo vogliono proprio...", Cronaca Sovversiva (6 sep. 1911). 
texto de Antonelli es del 5 de junio, es decir, antes de que se desarrollara la polémica. Así, la impresión de lo que acontecía, para quien presumiblemente sería el dirigente de los italianos, fue que ante las condiciones imperantes lo mejor era abandonar la causa.

En la edición de Regeneración, sezione italiana, del 2 de septiembre, Ludovico Caminita, con gran cantidad de insultos de por medio, aludió a otro texto de Galleani, "La tormenta messicana”, que cita en repetidas ocasiones. Galleani, basado en datos publicados por Hampton's Magazine, ofreció varios argumentos contra la posibilidad de que se desarrollara una revolución anarquista en México. Cabe señalar que dicha revista estaba dirigida a las clases adineradas del este de Estados Unidos y se oponía a las organizaciones de trabajadores. Emma Goldman realizó críticas y se involucró en el caso de los hermanos McNamara, acusados de colocar una bomba en el diario Los Angeles Times. ${ }^{45}$ Tuvo varios cambios editoriales y en estos años difundía artículos sobre viajes y textos de escritores conocidos, como Mark Twain o Jack London. Dicha revista fue la base de Galleani, quien argumentó que por tratarse México de un país con gran población indígena, 7000000 , cuatro de mestizos y apenas dos de criollos, con muy poca presencia de

${ }^{45} \mathrm{El}$ caso de los hermanos McNamara mantuvo la atención del público estadounidense durante los primeros meses de 1911. Uno de los abogados involucrados fue Job Harriman, mismo que defendió a los miembros del plm del cargo de violar las leyes de neutralidad. Harriman, uno de los dirigentes socialistas más conocidos en California, abandonó el caso de Ricardo y Enrique Flores Magón, Librado Rivera y Anselmo Figueroa debido a las manifestaciones de anarquismo, que fueron cada vez más frecuentes de mediados de 1911 en adelante. 
europeos, el anarquismo no tenía posibilidades de instituirse. Existía un catolicismo muy arraigado y en esas condiciones no consideraba la factibilidad del triunfo. ${ }^{46}$ Caminita, por su parte, argumentó que Zapata era el ejemplo de que la revolución económico social era posible y existían pruebas. Zapata expropiaba las tierras en diversos lugares de México y se trabajaban de forma comunal. La razón, semejante al argumento dado por Ricardo: los indígenas estaban acostumbrados al comunismo. El mexicano odiaba a la autoridad y al gobierno. Ninguna religión había impedido dicha práctica. ${ }^{47}$ Ricardo Flores Magón, en edición posterior, aseguró que eran 4000000 de indígenas. ${ }^{48}$

En la edición del 16 de septiembre los insultos contra Galleani por parte de Caminita fueron cuantiosos. La explicación ofrecida, sin embargo, permite señalar que en este contexto surgieron los comentarios desde los editores de Regeneración de repudiar públicamente el programa del Partido Liberal Mexicano de 1906. Afirmó Caminita que el documento fue resultado de los intereses de diversas tendencias, entre las cuales hubo jacobinos y socialistas anarquistas. Publicó que se relacionaron visiones opuestas. Los anarquistas debieron esperar a que las condiciones fueran propicias para realizar cambios de fondo en la organización.

\footnotetext{
${ }^{46}$ Luigi Galleani, "La tormenta messicana", en Cronaca Sovversiva (19 ago. 1911). En su largo texto del 7 de agosto, Galleani muestra conocer en detalle el proceso revolucionario en México.

47 Ludovico Caminita, "Forse che si forse che no. Il fonografo dell'Hampston’s Magazine”, Regeneración, sezione italiana (2 sep. 1911). ${ }^{48}$ Ricardo Flores Magón, “'Terra e libertà’”, Regeneración, sezione italiana (9 sep. 1911). La aclaración al final de la primera columna de la segunda página.
} 
Señaló que unos cuantos no podían transformar al partido en anarquista. Pero la minoría socialista anarquista actuaba con fuerza dentro del partido para convertirse en mayoría. Como prueba de su argumento, citó una carta de 1908, de Ricardo a Praxedis G. Guerrero, en la que asentó que en el partido solo había cuatro anarquistas: Enrique y Ricardo Flores Magón, Librado Rivera y el propio destinatario de la carta. Sobre Antonio I. Villareal y Juan Sarabia se indicó que tenían una preponderancia incontrastable..$^{49}$ Esta afirmación por sí sola obliga a repensar la idea de que el PLM era de seguidores de Ricardo (el llamado "magonismo"), ya que este es quien señala el papel de Sarabia y Villareal en la organización. Las instrucciones generales revolucionarias, aludidas por Galleani, fueron publicadas cuando predominaban en la organización Sarabia y Villareal. Caminita señaló que debía hacerse caso al manifiesto a los trabajadores de todo el mundo, publicado el 8 de abril de 1911. Ese era el documento al que se debía aludir, no a las instrucciones generales elaboradas bajo el predominio de Villareal y Sarabia, que para ese momento eran citados en numerosas ocasiones como traidores, burgueses, reformistas, maderistas y personalistas, entre otros epítetos. Cronaca Sovversiva en los meses siguientes siguió publicando tanto el Programa de 1906 como las instrucciones generales. La intención era demostrar que la junta de Los Ángeles era de reformistas, burgueses, seguidores de Madero. Por su parte, Caminita insistió en que la revolución que realizaban Zapata y Juan Banderas

49 Firmado por Regeneración, "Patadas de ahogado. Gli ultimi rantoli di Luigi Galleani”, Regeneración, sezione italiana (16 sep. 1911). En varias ocasiones los textos se firmaron como Regeneración, en alusión a que se trataba de un documento de los integrantes de la junta del PLM. 
era la verdadera; lo de Tijuana había sido obra de bandoleros estadounidenses. Y como se asentó desde julio de 1911, el PLM no era responsable de lo sucedido en dicho lugar.

Los argumentos de Galleani no se transformaron a lo ya asentado. Por otra parte, este es el contexto en el cual se publicó el programa del 23 de septiembre de 1911. Fue decirle a la comunidad anarquista del mundo que se hacía a un lado el rancio programa de 1906 para tomar el nuevo que de manera abierta manifestaba ser anarquista y que contaba además con muchos seguidores en México.

Lo señalado sobre Tijuana carecía de importancia, era un microscópico villorrio en la frontera. Pero sobre todo, fue una acción realizada por un grupo de bandoleros estadounidenses, unos vagabundos. ${ }^{50}$ Resaltamos estas afirmaciones puesto que existe una bibliografía amplia que insiste en que se trató de un complot de diarios y empresarios californianos para desprestigiar al grupo armado. Sin embargo, es de parte de los anarquistas del PLM de donde salen dichas afirmaciones. La razón no resultó conveniente para atraer anarquistas europeos. El interés era demostrar que la revolución económico social se realizaba en otras partes del país. Dicho de otra manera, si en mayo de 1911 se exaltó la toma de Tijuana como un gran triunfo de los liberales - como lo hacían los anarquistas del PLM -, en los meses siguientes era un estorbo.

A partir de la edición del 23 de septiembre, Regeneración, sezione italiana publicó un recuadro en el que cuestionaba varias de las afirmaciones de Luigi Galleani. El reclamo

${ }^{50}$ Firmado por Regeneración, “Miserere”, Regeneración, sezione italiana (23 sep. 1911). 
fundamental era no tomar en cuenta una serie de acciones del PLM en sus comentarios. Caminita y Ricardo centraron la atención en remarcar la contradicción de Galleani. Citaron textos de meses atrás, cuando el editor de Cronaca los apoyaba con entusiasmo. ${ }^{51}$ De dichos escritos se desprende lo que apuntamos en las primeras páginas de este escrito: la relación con los anarquistas de Paterson y Barre tenía varios meses. El proyecto de los anarquistas del PLM era la revolución mundial. No en Baja California o en México. El programa de 1906 era solo una forma de obtener seguidores, no el fin.

\section{LES TEMPS NOUVEAUX: DESDE EUROPA}

La publicación anarquista francesa Les Temps Nouveaux, editada por Jean Greave, se sumó a las afirmaciones sostenidas por los editores de Cronaca Sovversiva. Luigi Galleani, Filippo Perrone, Ernesto Teodori y John Luongo, por mencionar a quienes más escribieron, encontraron apoyo contra Regeneración en sus dos ediciones, en italiano y español, así como contra L'Era Nuova. El 30 de septiembre, Les Temps Nouveaux publicó un texto de E. Rist, en el cual se aclaraban las razones de la disputa entre Cronaca Sovversiva y Regeneración. Tijuana y Zapata fueron claves en la explicación dada por Rist. Afirmó que Tijuana era un pueblito fronterizo en el cual, a pesar de varios comentarios, no hubo nunca una colonia comunista. Rist aludía a publicaciones

\footnotetext{
${ }^{51}$ Firmado por Regeneración, "Inqualificabile”, Regeneración, sezione italiana (7 oct. 1911). En esta edición se publican extractos de documentos que circularon entre ellos, así como de grupos de Kansas. La información ayuda a comprender la dinámica de las comunicaciones entre los anarquistas de varias ciudades de Estados Unidos.
} 
realizadas por Il Libertario, editado en París, en el cual se asentó dicha afirmación. El poblado, ubicado $20 \mathrm{~km}$ al sur de San Diego, estaba formado por una cuarentena de casas. Se localizaba en una planicie detrás de un cerro y no era donde las propuestas de Kropotkin y Bakunin se llevaban a la práctica. La notoriedad del lugar tenía que ver con el interés de los californianos por establecer centros de diversión. La concesión de un hipódromo era el motivo de atención de los empresarios. ${ }^{52}$

Estas afirmaciones fueron destacadas en Cronaca con la clara intención de demostrar que la revolución anarquista no se llevaba a cabo. En el marco de diversos vituperios señaló que los insultos recibidos por personas de Kansas y otros lugares eran para defender a un grupo de cowboys en Tijuana. El texto de Rist indicó que Zapata era presentado como un verdadero revolucionario comunista, comparable con los más fieros luchadores, como Espartaco. Zapata, al frente de los "magonistas", llevaba la revolución social a todas partes. La ironía en el texto de Galleani y las afirmaciones de Rist dejaban en claro que no había tal revolución anarquista.

Cavallazzi, desde Barre, Vermont, en noviembre de 1911, le escribió a Jean Grave su punto de vista de lo que sucedía entre Cronaca y Regeneración. El autor ofreció argumentos en el sentido de que Cronaca no negaba que existiera una revolución, sino que tuviera como fin la instauración del comunismo. Aseguró: "creer que en México se esté hoy a la víspera de la realización de una sociedad comunista y

52 "Ancora un paio d'infamia”, Cronaca Sovversiva (11 nov. 1911). El resumen y la selección de las notas está signado por la redacción, lo que hace suponer que es Luigi Galleani. 
que este movimiento emancipador pueda extenderse poco a poco y en breve lapso a los Estados Unidos, es demostrar una simpleza verdaderamente lamentable por parte de los revolucionarios". Retoma en pregunta una de las afirmaciones de Galleani y reelaborada por Rist:

$[\ldots]_{\text {¿ }}$ cómo se puede creer que un pueblo muy dividido por cuestiones de raza, de lenguaje; por razones de geografía; fuertemente imbuido de supersticiones religiosas, que ha vivido hasta ayer bajo la dictadura porfiriana, que nunca ha tenido la menor noción del problema social, pueda de un día para otro pensar seriamente en el comunismo?53

Posteriormente, Cavallazzi hizo referencia al programa de julio de 1906, las instrucciones generales ya mencionadas, y retomó a Galleani al señalar que dichos documentos no eran libertarios. Indicó un aspecto que consideramos debe analizarse con mayor atención. La prensa ácrata tomaba como válidas las afirmaciones de Regeneración y esta información, redactada sobre todo por Ricardo, era reproducida por otros anarquistas. Y la conclusión de Cavallazzi fue que "[...] es con base en una sola y única fuente que se nutre nuestra prensa. Aparte de esto, sólo hay artículos más o menos ditirámbicos que, demasiado a menudo, revelan en el autor ciertamente a un camarada entusiasta, pero que no sabe una palabra de México". Posteriormente afirmó:

Pero lo que asombra mucho más, es la manera ligera con que se mencionan noticias alarmistas de la prensa burguesa. Basta

53 Les Temps Nouveaux (18 nov. 1911). La carta se puede consultar en antorcha.net 
con que un periódico capitalista relate un incidente cualquiera inflándolo, para que este incidente sea tomado en serio y reproducido. Al proceder de esta manera, sólo leyendo los periódicos americanos, somos llevados a creer que Europa se debate en fuego y llamas al menos dos veces al año. ¿Es esto serio? De ninguna manera lo puedo creer. $^{54}$

Así, la afirmación de Cavallazzi no solo da un punto de vista sobre la disputa y qué clase de revolución era, sino cómo debe leerse lo publicado en Regeneración. Si bien volveremos a ello en otros escritos, consideramos oportuno indicar que buena parte de la historiografía sobre el tema del PLM, así como en lo referente a lo sucedido en Baja California, ha sido escrita a partir de criterios semejantes.

OCTUBRE DE 1911-FEBRERO DE 1912

Como ya apuntamos, el 6 de mayo de 1911 en las páginas de Regeneración se afirmó que el programa del Partido Liberal Mexicano fue elaborado por Juan Sarabia. De igual forma, hemos indicado que Ludovico Caminita publicó una carta de 1908 en la que se afirmó que tal documento fue elaborado por la fracción mayoritaria del PLM, a la cual no pertenecían Ricardo y Enrique Flores Magón, Praxedis G. Guerrero ni Librado Rivera. Sin embargo, consideramos oportuno destacar que es un aspecto fundamental en la estrategia de los anarquistas del PLM. Necesitaban desligarse de dicho documento en función de las acusaciones que surgieron desde Cronaca Sovversiva.

${ }^{54}$ Les Temps Nouveaux (18 nov. 1911). 
Luigi Galleani, además de publicar textos directos contra Ricardo y Ludovico, apoyado en los autores del documento del 17 de junio, quienes reaparecen con comentarios en varias ocasiones, cuestionó el cambio de programa y la forma en que se hizo. Además, se utilizó el término de filibusteros para calificar a quienes ocuparon Tijuana. Con ello, sumamos otro argumento más para los autores que de manera fácil y sin sustentarlo afirman que el supuesto "complot” fue inventado por Rómulo Velasco Ceballos en 1919 en la obra ¿ Se apoderará Estados Unidos de América de la Baja California? La invasión filibustera de 1911. En el contexto que aquí desarrollamos apareció con fines de minimizar la importancia de la toma de Tijuana y de descalificar las acciones desde la visión de los anarquistas italianos que llegaron al poblado.

El efecto de la publicación del programa del 23 de septiembre de 1911 fue que Galleani destacó la contradicción en los planteamientos: de un deleznable y patético programa burgués como el de 1906, a un texto donde se planteaba la abolición de la propiedad privada. Hizo hincapié en la contradicción entre los documentos del PLM, como el programa de 1906 y las instrucciones, con textos de Ricardo, como uno del 3 de septiembre de 1910 con claras alusiones al anarquismo, pero en el que se menciona como plan de lucha el programa de 1906. Galleani destacó la pregunta ¿Perche mentire? (¿Por qué mentir?). Con base en ello, mencionó la supuesta alianza con Madero, de quien nada había que esperar por su condición burguesa. En esta línea, se sostuvieron otros textos publicados por Cronaca Sovversiva.

En edición posterior Galleani, el 28 de octubre, resaltó el cambio de programa, para afirmar que se trataba de un 
anarquismo improvisado. Se había modificado en una semana, sin discusión, sin consenso. Pero, además, se había escondido un ideal por el cual se luchaba con el pretexto de no perder simpatizantes. Por ello no creía en el anarquismo de la junta de Los Ángeles, como tampoco que la revolución mexicana fuera económico social. Cronaca Sovversiva había apoyado a todos, Sarabia, Villareal, Flores Magón, pero a pesar del entusiasmo, todo era producto de la imaginación de la junta de Los Ángeles. Además, desconfiaba de la relación entre los miembros del PLM con Madero, quien encabezaba una revolución política que no valía la pena apoyar. Cabe señalar que de igual forma se sustentó en comentarios de Les Temps Nouveaux. Por su parte Ernesto Teodori, de manera directa, señaló a Ricardo que llegaron con entusiasmo a luchar, pero se encontraron con algo decepcionante. A pesar de sus convicciones lo mejor era irse, puesto que no había ética anarquista en el movimiento. ${ }^{55}$ Incluso, a principios de octubre, entre alguna prensa ácrata, se difundió la idea de que los firmantes del documento del 17 de junio se habían retractado, a lo que se aclaró que bajo ninguna circunstancia, sobre todo de parte de Teodori. Cabe apuntar que otros grupos de Spring Valley, California, o de Tampa, Florida, intervinieron en la discusión, tanto para intentar apoyar a la junta de Los Ángeles, los primeros, como para resaltar que el enfrentamiento entre Regeneración y L'Era Nuova contra Cronaca resultaba vergonzoso para todos los anarquistas. ${ }^{56}$

${ }^{55}$ Filippo Perrone, "Triste causa quella che si raccomanda soltanto alla menzogna! a Riccardo Flores Magon”, Cronaca Sovversiva (7 oct. 1911). La carta está incluida en el texto de Luigi Galleani.

${ }^{56}$ Círculo de estudios sociales de Barre, Vermont, "Al gruppo germinal di Spring Valley”, Cronaca Sovversiva (21 oct. 1911). 
Filippo Perroni, luego de negarse a participar en la polémica, publicó una carta donde acusó a Ricardo Flores Magón, Caminita y Cravello, además de ser maderistas, de falta de honestidad, sobre todo para el caso de Ricardo. Éste había inventado una revolución en el papel - apoyado en una bola de bandidos, afirma - con el objetivo de conseguir dinero para financiar Regeneración en versión italiana. Se había regado por Europa y por el mundo una falsa revolución y eso era una falta de honestidad. ${ }^{57}$ Era un movimiento de cowboys del viejo oeste, no de anarquistas. Así como Perrone fue acusado de ser maderista, éste insistió en que el verdadero agente de Madero era Flores Magón. Es claro que ninguno tenía relación con Madero, pero para un anarquista, eso era un insulto.

En la versión italiana de Regeneración, a finales de octubre se llamó a toda la comunidad italiana a sumarse a la revolución económico social que se realizaba. Emiliano Zapata estaba a las puertas de la Ciudad de México y en cualquier momento la tomaría. La bandera roja ya estaba en todo el país, los mexicanos habían vivido el comunismo y estaban a punto de volver a ello, por tanto, los italianos debían seguir el ejemplo y acudir a ayudar. No se trataba de una utopía, sino de algo que ya estaba sucediendo y los miles de seguidores de la guerrilla zapatista gritaban "viva el socialismo", por tanto, la comunidad internacional no podía ser indiferente ante una realidad tan evidente..$^{58}$

\footnotetext{
57 Filippo Perrone, "Cravello sputacchiato da Perrone... Magon sbugiardato da Figueroa”, Cronaca Sovversiva (4 nov. 1911). La carta está firmada el 23 de octubre en Chicago, Illinois.

58 Ludovico Caminita, "Viva la rivoluzione sociale”, Regeneración, sezione italiana (28 oct. 1911).
} 
A finales de octubre terminó la publicación de Regeneración en italiano, sin embargo, aparecieron notas que mantuvieron la discusión en Regeneración en español. La nueva misión de Ludovico Caminita consistió en impartir conferencias sobre la revolución anarquista que supuestamente se desarrollaba en México. Por su parte, los de Barre concluyeron una vez más que ellos no creían en la revolución anarquista de México, pero, sobre todo, cada quien era libre de ir o no. El movimiento armado relatado por Ricardo sólo estaba en su imaginación y lo compararon con Sancho Pan$\mathrm{za} .{ }^{59}$ En este contexto, en diciembre de 1911 los anarquistas de Barre indicaron que el movimiento de Baja California era de una banda de filibusteros. Ricardo Flores Magón fue atacado duramente por Galleani, quien contó con el apoyo de un grupo de Boston. ${ }^{60}$

En ese contexto, Henry Martin, quien estuvo en Tijuana durante el mes de mayo, publicó una carta en la que describió su punto de vista. Su entusiasmo había sido evidente al sumarse al movimiento, pero Luigi Galleani nunca hizo acto de presencia, se limitó a enardecer pero no a hacer. Éste se quedó en la comodidad de su casa, en lugar de dirigir a miles de hombres en el combate. Galleani alentó a otros, pero no hizo nada. ${ }^{61}$ El héroe anarquista de Paterson, en

59 Carlo Prato et al., "Mexicana. Invece di un manifesto", Cronaca Sovversiva (25 nov. 1911). Cabe señalar que el texto está firmado por 20 italianos que no habían participado en la discusión.

${ }^{60}$ Luigi Galleani, "Falsario", Cronaca Sovversiva (2 dic. 1911). Entre los anarquistas de Boston que comentaron contra la ilusoria revolución mexicana, estaban Libero Tancredi - uno de los firmantes del documento del 17 de junio-Carlo Solari y Giuseppe Solari.

${ }^{61}$ Firmado por la redacción "Mexicana. Delusione", Cronaca Sovversiva (30 dic. 1911). En la nota aparece la carta de Henry Martin. 
resumen, no había estado a la altura de las circunstancias. Martin hizo la alusión de que inspirarse en Ravachol no sirvió para impulsar la revolución anarquista.

En la misma edición apareció una carta de Sebastiano Messaglia, quien también estuvo en Tijuana. Messaglia reprochó a Libero Tancredi por preferir comprarse un traje de 300 dólares en lugar de adquirir armas. Caminita, Cravello y Magón felicitaban pero no hacían nada, el entusiasmo y los discursos que transmitían de poco sirvieron. Destacó la permanencia de Ricardo en Los Ángeles, donde se dedicaba a cantar la internacional y a fabular sobre la revolución comunista en la árida Baja California. Era muy fácil que otros hicieran las cosas y de manera directa le reclamó a Ricardo su nula participación y lo calificó de empresario. El pueblo de Tijuana no se involucró en la revolución, por el contrario, las familias se refugiaron en Estados Unidos, donde padecieron frío y hambre. Los indígenas que supuestamente estaban preparados para el comunismo no llegaron nunca. De manera reiterada destacó que de hombres como Pryce no podía salir nada relacionado con los anarquistas. Era, pues, en sus palabras, una banda de filibusteros e ironizó que, de tierra y libertad, sólo hubo libertad para la prostitución, el alcohol y los abusos en autos. Personas gritaron "tierra y libertad", pero se dedicaron a robar. Eran, pues, unos cowboys sin propósitos, unos ladrones sin bandera. ${ }^{62}$

Por su parte, Ernesto Teodori reafirmó la tesis de que por el catolicismo de los mexicanos no era factible la realización del anarquismo. En diciembre de 1911, en las páginas

${ }^{62}$ Firmado por la redacción "Mexicana. Delusione”, Cronaca Sovversiva (30 dic. 1911). En la nota aparece la carta de Sebastiano Messaglia. 
de Regeneración, se publicó una carta donde se afirmó que por la presencia de los italianos la junta del Partido Liberal debió cambiar el programa de 1906 y modificarlo por el anarquista del 23 de septiembre de 1911. Dicha afirmación fue negada por Caminita al mencionar textos anteriores, sobre todo el llamado a los trabajadores del mundo del 8 de abril. Al respecto, nosotros afirmamos que si bien hubo claras manifestaciones de anarquismo desde antes, incluso desde 1904, sí fue importante para terminar con un doble discurso que hasta la fecha ha merecido poco análisis. La presencia de los italianos, donde debemos destacar a Caminita y Cravello, sí conllevó un discurso abiertamente anarquista. Digno es de mencionarse la inclusión como ejemplo a seguir de los anarquistas que participaron en acciones contra primeros ministros, reyes, príncipes o presidentes, como Ravachol, Émily Henry o León Czolgosz. De igual forma, se inició una retórica contraria al programa del PLM de 1906 y de los socialistas, a quienes se presentaba como simples reformadores y negociadores con los gobiernos.

En los primeros meses de 1912 se mantuvo la discusión en Cronaca y Regeneración, incluso hubo un encuentro entre Perroni y Caminita. Este último quería que se reconociera que Tijuana no era México; lo sucedido en la población fronteriza no reflejaba lo que en realidad estaba pasando: la expropiación de la tierra y los medios de producción en manos del pueblo mexicano, mismo que, por haber vivido el comunismo, volvía a su práctica gracias a la difusión de ideas realizada por ellos. Como ya apuntamos, para Caminita lo de Tijuana fue hecho por un grupo de bandidos, de cowboys estadounidenses sin apego al ideal anarquista. 
UNA POLÉMICA QUE SE VOLVIÓ PERMANENTE. Y UNA PARADOJA

Desde 1911 en adelante la revolución económico social en las páginas de Regeneración era una realidad. Las referencias para "los que dudan" aparecieron en numerosas ocasiones en años posteriores. Para los editores de Regeneración era una revolución comunista, anarquista: era lo que entendían por revolución económico social. Emiliano Zapata, a pesar de ciertas críticas en varios momentos, era el encargado de llevarla a cabo, puesto que seguía, supuestamente, los preceptos de Kropotkin, el autor que movía al campesinado mexicano. El proletariado mundial debía seguir el ejemplo.

Cronaca Sovversiva y los anarquistas italianos que estuvieron en Tijuana fueron quienes iniciaron esta discusión, pero ésta se mantuvo con otras publicaciones ácratas en los años posteriores. Les Temps Nouveuax la retomó y negó la posibilidad de que el anarquismo fuera la verdadera lucha de México. Por ello, el reclamo de los editores de Regeneración fue que los ataques que más afectaban a la causa eran los de quienes se suponía debían ayudarlos. La paradoja es que la estrategia de Ricardo consistió en convocar a italianos y españoles anarquistas, pero los italianos fueron los que negaron la posibilidad de que en México hubiera condiciones para sus propósitos. Su argumento fue que las creencias religiosas, la ignorancia y la falta de europeos blancos eran el impedimento. Así, los llamados, en quienes se depositó la esperanza, por quienes se planeó una estrategia, fueron opositores a que los fines del movimiento fueran comunistas. Además, se encargaron de difundir la idea de que todo era una ilusión, sobre todo de Ricardo. Era una rivoluzione da 
tavolino, de mesita, inventada en el papel de los editores de Regeneración. La toma de Tijuana en mayo, lejos de ayudar a la causa ácrata, fue un factor negativo para atraer más anarquistas. Para los autores que ven seguidores de Magón en Baja California y mencionan una "campaña magonista", o "magonistas", ${ }^{63}$ sin analizar la composición del grupo armado y sus profundas diferencias, este factor representa una dificultad más para sostener dicha tesis. En este escrito demostramos que estuvieron de acuerdo, tanto Regeneración en italiano como Cronaca Sovversiva, en que los hombres que ocuparon Tijuana eran bandoleros, cowboys sin ideología. Para ambas publicaciones, Pryce estaba lejos de representar la verdadera revolución.

Así, es común que autores se refieran a lo sucedido en el Distrito Norte de la Baja California como la "verdadera revolución”, la "otra revolución”, la revolución alternativa. La paradoja es que los anarquistas del PLM la desconocieron como suya. Su argumento publicado en los dos idiomas de Regeneración fue que se trataba de algo ajeno y no eran responsables de lo sucedido. Los italianos que publicaron en Cronaca también describieron al grupo armado como filibusteros. Así, el sector anarquista de italianos en Estados Unidos más buscado por los anarquistas del PLM se convirtió en uno de sus principales críticos ante la comunidad ácrata. Para los italianos, lo mismo era Tijuana que todo México; el movimiento debía ser anarquista, sin ubicar las diferencias regionales del movimiento armado. Las

${ }^{63}$ Samaniego, “'El magonismo no existe”, pp. 33-52. En el artículo señalamos las razones por las que los anarquistas del PLM se negaban a ser identificados como "magonistas". 
afirmaciones de que era una revolución anarquista y que por contagio se expandiría a todo el mundo permitieron un apoyo temporal que se diluyó ante la diversidad de intereses de parte de los ocupantes de Tijuana.

Como apuntamos al inicio del presente escrito, las disputas del PLM contra socialistas, maderistas, otros miembros del PLM, algunos integrantes de la IWw y muy pronto, entre ellos mismos, como fue la disputa con Rafael Romero Palacios, son parte de un entorno más complejo de lo que aquí hemos destacado. Sin embargo, la discusión con los anarquistas de Barre obliga al análisis de la estrategia de los anarquistas del PLM; de igual forma, a replantear la necesidad de ubicar a Regeneración como parte de un proyecto de revolución mundial. En ello se debe incluir porque toman la figura de Emiliano Zapata como símbolo de su lucha anarquista, cuando el mencionado estaba lejos de seguir dicho proyecto. En ese sentido, apuntamos que los términos tierra y libertad tuvieron significados distintos para unos y otros.

\section{REFERENCIAS}

Blaisdell, Lowell L.

The Desert Revolution, Wisconsin, The University of Wisconsin Press, 1962.

BLANQUEL, Eduardo

"El anarco-magonismo", en Historia Mexicana, XIII: 3 (51) (ene.-mar. 1964), pp. 394-427.

Hernández Padilla, Salvador

El magonismo: historia de una pasión libertaria, 1900-1922, México, Ediciones Era, 1984. 
Martínez, Pablo L.

Elmagonismo en Baja California (documentos), México, Baja California, 1958.

Novak, D.

"Anarchism and Individual Terrorism", en The Canadian Journal of Economics and Political Science/ Revue canadienne d'économique et de science politique, 20: 2 (mayo 1954), pp. 176-184.

Samaniego López, Marco Antonio

Nacionalismo y revolución. Los acontecimientos de 1911 en Baja California, Tijuana, Baja California, Universidad Autónoma de Baja California, Consejo Nacional para la Cultura y las Artes, Centro Cultural Tijuana, 2008.

"El impacto del maderismo en Baja California, 1911", en Estudios de Historia Moderna y Contemporánea, 18 (1999).

"La rebelión indígena de Emilio Guerrero en Baja California”, en Eslabones, Ir: 11 (ene.-jun. 1996), pp. 114-131.

“'El magonismo no existe’: Ricardo Flores Magón”, en Estudios de Historia Moderna y Contemporánea, 49 (2015), pp. 33-53.

Taylor Hansen, Lawrence Douglas

La campaña magonista de 1911 en Baja California, Tijuana, El Colegio de la Frontera Norte, 1992.

Torrés PARÉs, Javier

La revolución sin frontera. El Partido Liberal Mexicano y las relaciones entre el movimiento obrero de México y el de Estados Unidos. 1900-1923, México, Universidad Nacional Autónoma de México, Ediciones Hispánicas, 1990.

Trejo, Rubén

Magonismo. Utopia y revolución, 1910-1913, Barcelona, España, Aldarull Edicions, 2010. 
Zimmer, Kenyon

Immigrants against the State: Yiddish and Italian Anarchism in America, Ililnois, University of Illinois, 2015, pp. 78-79.

Hemerografía

Cronaca Sovversiva, Barre, Vermont, Estados Unidos.

Deseret Evening News, Salt Lake City, Utah, Estados Unidos.

Il Libertario, París, Francia.

Les Temps Nouveaux, París, Francia.

L'Era Nuova, Paterson, Nueva Jersey, Estados Unidos.

New York Times, Nueva York, Estados Unidos.

The Emancipator, Home, Washington, Estados Unidos.

The Salt Lake Tribune, Salt Lake City, Utah, Estados Unidos.

The Saint Louis Republic, Saint Louis, Missouri, Estados Unidos.

The San Francisco Call, San Francisco, California, Estados Unidos.

Regeneración, Los Ángeles, California, Estados Unidos.

Regeneracion, sezione italiana, Los Ángeles, California, Estados Unidos.

San Diego Union, San Diego, California, Estados Unidos.

Tierra y Libertad, Barcelona, España. 
